\title{
TESTING NOVEL CR-39 DETECTOR DEPLOYMENT SYSTEM FOR IDENTIFICATION OF SUBSURFACE FRACTURES, SODA SPRINGS, ID
}

Travis McLing, Michael Carpenter, William Brandon, Bernie Zavala

June 2015

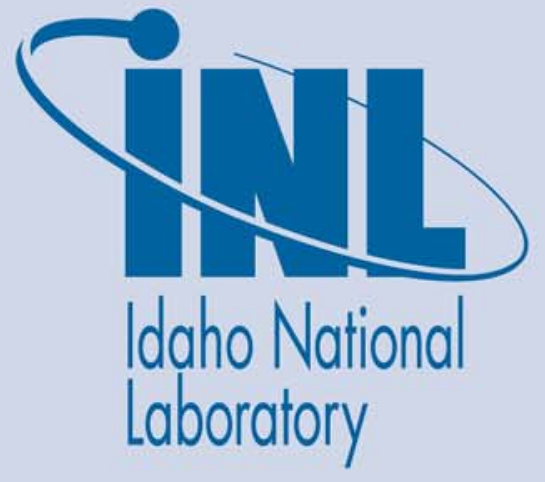

The INL is a U.S. Department of Energy National Laboratory operated by Battelle Energy Alliance 


\title{
TESTING NOVEL CR-39 DETECTOR DEPLOYMENT SYSTEM FOR IDENTIFICATION OF SUBSURFACE FRACTURES, SODA SPRINGS, ID
}

\author{
Travis McLing, Michael Carpenter, William Brandon, Bernie Zavala
}

June 20152005

\author{
Idaho National Laboratory \\ Idaho Falls, Idaho 83415
}

http://www.inl.gov

Prepared for the

U.S. Department of Energy

Office of Environmental Protection Agency

Under DOE Idaho Operations Office

Contract DE-AC07-05ID14517 


\title{
TESTING NOVEL CR-39 DETECTOR DEPLOYMENT SYSTEM FOR IDENTIFICATION OF SUBSURFACE FRACTURES, SODA SPRINGS, ID INL/EXT-15-34802
}

Travis McLing (Idaho National Laboratory); 2) Michael Carpenter (Idaho National Laboratory); 3) William Brandon (US EPA Region 1); 4) Bernie Zavala (US EPA Region 1)

\begin{abstract}
The Environmental Protection Agency (EPA) teamed with Battelle Energy Alliance, LLC (BEA) at Idaho National Laboratory (INL) to facilitate further testing of geologic-fractureidentification methodology at a field site near the Monsanto Superfund Site located in Soda Springs, Idaho. INL had the necessary testing and technological expertise to perform this work. Battelle Memorial Institute (BMI) engaged INL to perform this work through a Work for Others (WFO) Agreement. This study continued a multi-year collaborative effort between INL and EPA to test the efficacy of using field deployed Cr-39 radon in soil portals. This research enables identification of active fractures capable of transporting contaminants at sites where fractures are suspected pathways into the subsurface. Current state of the art methods for mapping fracture networks are exceedingly expensive and notoriously inaccurate. This project evaluated the applicability of using cheap, readily available, passive radon detectors to identify conductive geologic structures (i.e. fractures, and fracture networks) in the subsurface that control the transport of contaminants at fracture-dominated sites. The work utilized proven off-the-shelf technology in the form of CR-39 radon detectors, which have been widely deployed to detect radon levels in homes and businesses. In a separate collaborative EPA/INL study outside of this workscope, CR-39 detectors are being utilized to determine the location of active transport fractures in a fractured granitic upland adjacent to a landfill site at the Fort Devens, MA that EPAdesignated as National Priorities List (NPL) site. The innovative concept of using an easily deployed port that allows the CR-39 to measure the Rn-222 in the soil or alluvium above the fractured rock, while restricting atmospheric Rn-222 and soil sourced Ra from contaminating the detector is unique to INL and EPA approach previously developed. By deploying a series of these inexpensive detector-casing combinations statistical samples of the Rn-222 flux can be measured, elucidating the most communicative fractures (i.e. fractures that are actively transporting water and gasses). The Rn-222 measurements can then be used as an input to create a more accurate conceptual model to be used for transport modeling and related cleanup activities. If the team's approach is demonstrated to be applicable to a wide variety of rock types and soil conditions it might potentially offer significant cost saving without a reduction in data quality at Monsanto Superfund and other sites underlain by fracture-dominated bedrock.[I think you need to add a couple of sentences on the results and conclusions from this study]
\end{abstract}




\section{PROJECT: TESTING NOVEL CR-39 DETECTOR DEPLOYMENT SYSTEM FOR IDENTIFICATION OF SUBSURFACE FRACTURES, SODA SPRINGS, ID}

Investigators: Travis McLing (INL), William Brandon (U.S. EPA), Bernie Zavala (U.S. EPA), and Michael Carpenter (INL)

\section{General Description of the Project Including Objectives and Purpose.}

The Environmental Protection Agency (EPA) teamed with Battelle Energy Alliance, LLC (BEA) at Idaho National Laboratory (INL) to facilitate further testing of geologic-fractureidentification methodology at a field site near the Monsanto Superfund Site located in Soda Springs, Idaho. INL had the necessary testing and technological expertise to perform this work. Battelle Memorial Institute (BMI) engaged INL to perform this work through a Work for Others (WFO) Agreement. This study continues a multi-year collaborative effort between INL and EPA to test the efficacy of using field deployed Cr-39 radon in soil portals. This research enables identification of active fractures capable of transporting contaminants at sites where fractures are suspected pathways into the subsurface. Current state of the art methods for mapping fracture networks are exceedingly expensive and notoriously inaccurate. this project evaluated the applicability of using cheap, readily available, passive radon detectors to identify conductive geologic structures (i.e. fractures, and fracture networks) in the subsurface that control the transport of contaminants at fracture-dominated sites. The work utilized proven off-the-shelf technology in the form of CR-39 radon detectors, which have been widely deployed to detect radon levels in homes and businesses. In an existing collaborative EPA/INL study outside of this workscope,. CR39 detectors are being utilized to determine the location of active transport fractures in a fractured granitic upland adjacent to a landfill site at the Fort Devens, MA that EPAdesignated as National Priorities List (NPL) site. The innovative concept of using an easily deployed port that allows the CR-39 to measure the Rn-222 in the soil or alluvium above the fractured rock, while restricting atmospheric Rn-222 and soil sourced Ra from contaminating the detector is unique to INL and EPA approach previously developed. By deploying a series of these inexpensive detector-casing combinations statistical samples of the Rn-222 flux can be measured, elucidating the most communicative fractures (i.e. fractures that are actively transporting water and gasses). The Rn-222 measurements can then be used as an input to create a more accurate conceptual model to be used for transport modeling and related cleanup activities. If the team's approach is demonstrated to be applicable to a wide variety of rock types and soil conditions it might potentially offer significant cost saving without a reduction in data quality at Monsanto Superfund and other sites underlain by fracture-dominated bedrock.

The detector system is an exceedingly simple but effective tool. A PVC fixture is lowered into a casing that has been drilled into the soil. The PVC fixture holds the CR-39 detector in place during passive data acquisition. Based on the results of the 2012 Fort Devens study it was determined that further testing of the tool was needed at a different type of site. This new study was conducted in a high $\mathrm{CO}_{2}$ flux geologic environment located in the town of 
Soda Springs, Idaho. This Site is a significant departure from the conditions present at Fort Devens, Massachusetts, where the first study was conducted in 2012. Like Fort Devens, the water transport at the Monsanto Site is dominated by fractured rock. At the Monsanto Site the fractured rock is a series of low volume basalt flows deposited in the Blackfoot Valley Volcanic Field (BVF). Unique to this Site is the large amount of $\mathrm{CO}_{2}$, which emanates from the fracture network providing a constant flow of gasses, including Rn-222, through the fractures. The large flux of $\mathrm{Rn}-222$ bearing $\mathrm{CO}_{2}$ emanating from the fractures is ideally suited to test the teams methodology. Sample transects can be laid out to orthogonally intersect suspected high flux fractures. Specific tasks associated with this effort included the following:

- Assessing the cost and time required to deploy the technology at the Soda Springs location

- Quantifying the time required to construct the soil portals in the field

- Determining what tools are required to install the portals in alluvium covering the fractured rock (does installation require a power probe, a hand auger, a post-hole digger, etc.).

- Evaluating the CR-39 exposure time required for achieving the necessary signal to noise ratio needed for a statistical analysis of the data

- $\quad$ Determining the spatial resolution of the technique

- What is the minimum size of the fracture or fracture network that can be resolved with this tool?

- What is the detector spacing required to measure the features of interest?

\section{Background:}

The area around the Monsanto site is located in a very unique geologic setting, where large volumes of $\mathrm{CO}_{2}$ are produced at depth and migrate to the shallow subsurface. In places $\mathrm{CO}_{2}$ makes it to the surface through a series of fractures controlled by the regional stress field. However, under most of the area, the $\mathrm{CO}_{2}$ is prevented from migrating to the surface by an impermeable layer of mineralized basalt. This impermeable layer allows a highly pressurized reservoir of $\mathrm{CO}_{2}$ to form, that when penetrated by wells causes $\mathrm{CO}_{2}$ and water to geyser up to 40 meters into the air (Figure 1 ). The locations of the areas where large volumes of $\mathrm{CO}_{2}$ leak to the surface have long been identified and are in many cases local tourist attractions and are easily recognizable. However, the presence of smaller fracture sets where $\mathrm{CO}_{2}$ can leak to the surface and where contamination can infiltrate into the subsurface is hypothesized but unknown. This study at in the southern BVF (Figure 2) represents a unique opportunity to use well-established CR-39 radon detection technology in a new innovative to try and identify these types of fracture systems. 


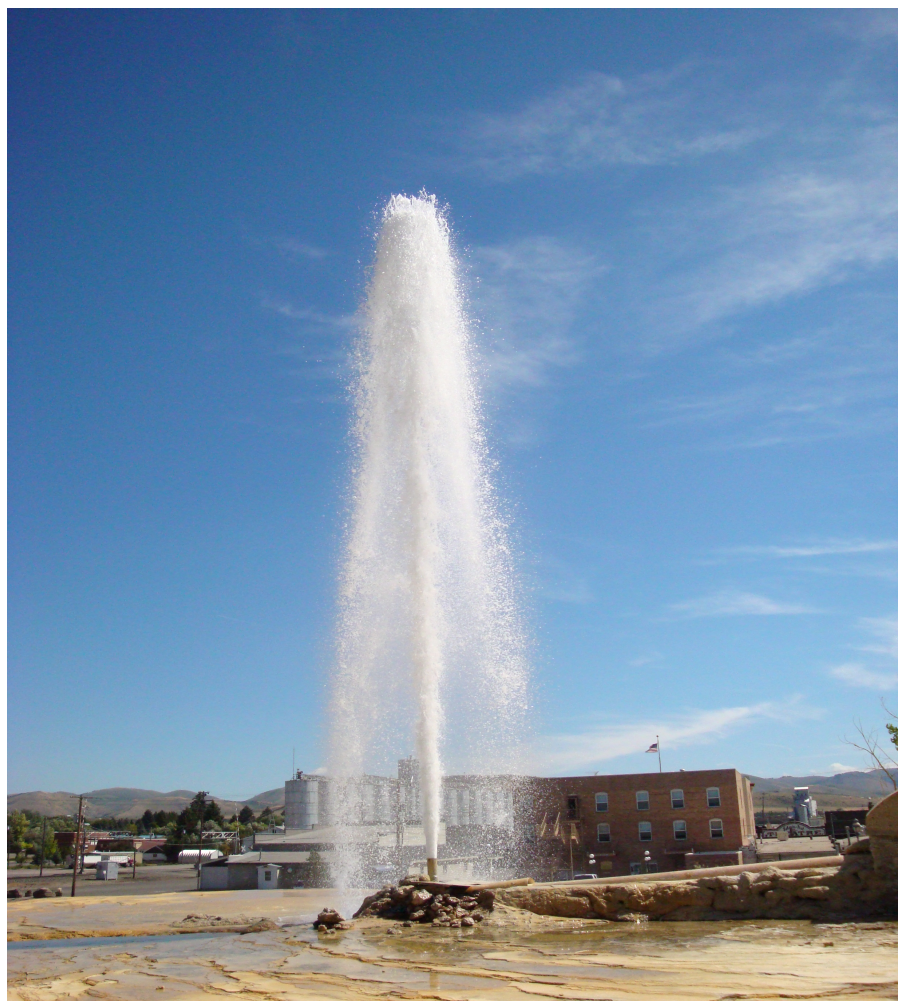

Figure 1. Soda Springs Geyser well, which is located in the center of the city. This well was drilled in 1937 by a group of Soda Springs businessmen who attempted to drill warm water well for a public swimming pool. The well penetrated to a depth of $96 \mathrm{~m}$, where it encountered a zone of highly pressurized warm $\mathrm{CO}_{2}$-charged water, which began to spontaneously erupt. The well casing is $61 \mathrm{~cm}$ in diameter, with discharge averaging more than $7.6 \mathrm{~m}^{3} /$ second and a surface temperature of approximately $28^{\circ} \mathrm{C}$. Discharged water rises more than $30 \mathrm{~m}$ into the air. The geyser well has been capped and has been allowed to erupt every hour as a tourist attraction for more than 75 years

\section{Regional Geologic Setting}

The study area (Figure 3) is located in southeastern Idaho, within the Sevier thrust belt and the northeastern-most Basin and Range province, where a thick succession of Paleozoic and Mesozoic sedimentary rocks have been thrust and compressed more than $150 \mathrm{~km}$ eastward toward the midcontinent over a period of 60 million years. These rocks subsequently have been faulted and displaced by Basin and Range extension over the last 10 million years, creating uplifted ranges and down-dropped valleys bounded by normal faults. In the region of the BVF, where Soda Springs is located, the down- dropped graben is filled with basalt flows of the Blackfoot Lava Field and associated intercalated sediment. Regionally, normal faults are associated with east-west Eocene to Holocene extension controlled fault-block mountain ranges and adjacent sedimentary basins and overprint Cretaceous to early Tertiary thrust faults and folds (Armstrong 1969, Armstrong and Oriel 1965). Important to development of the BVF system is its location proximal to the Eastern Snake River Plain (ESRP) Volcanic Province that is believed to have provided the thermal driving force for 
emplacement of both the BVF and the proximal Gem Valley lava fields. Unlike the BVF volcanic field, ESRP has been extensively studied, and because of their similarities, a lot of the data from ESRP are applicable to the BVF.

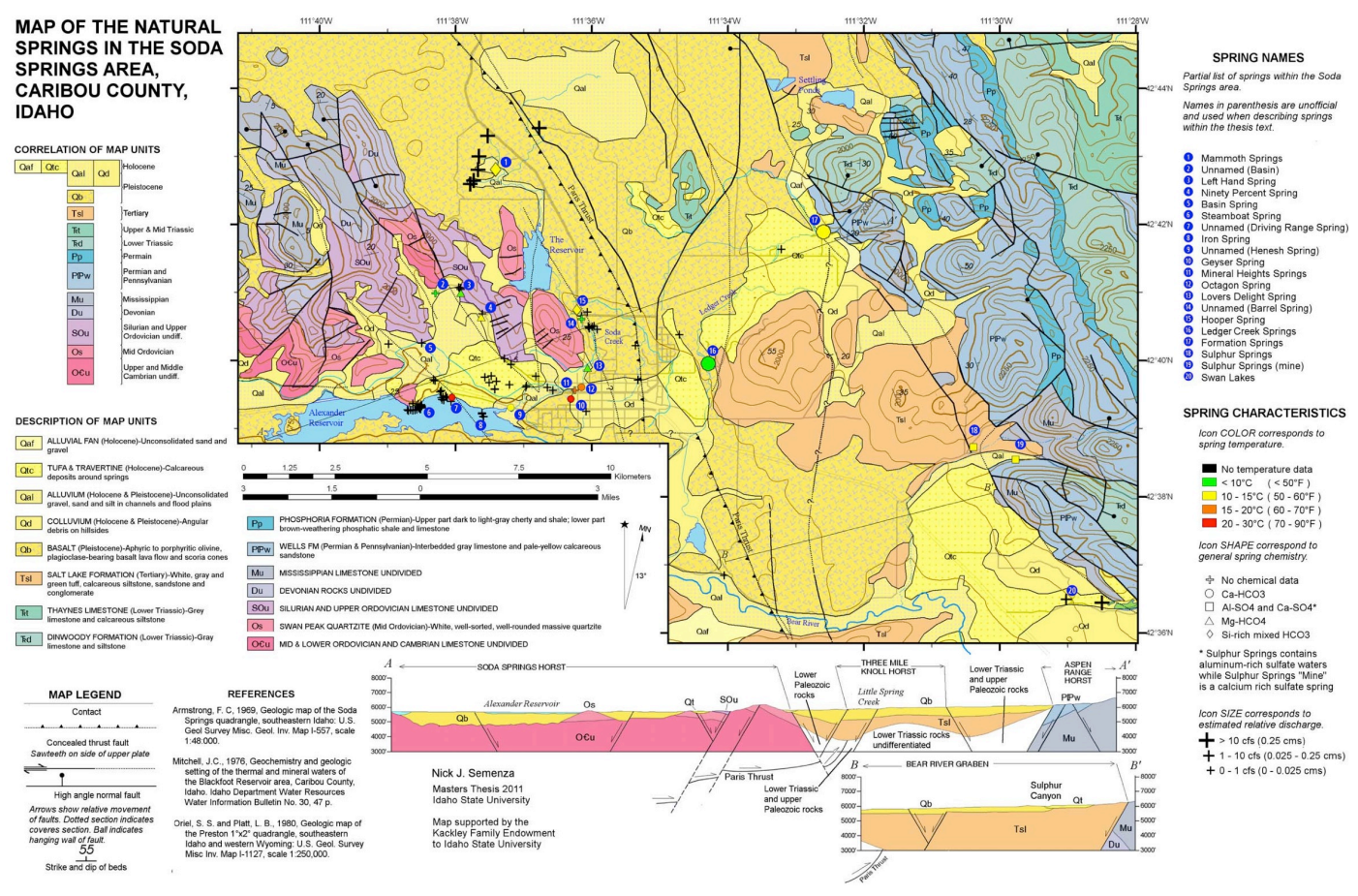

Figure 2 Geologic setting and freatures of inerest for the Soda Springs site located in the souther BVF. 

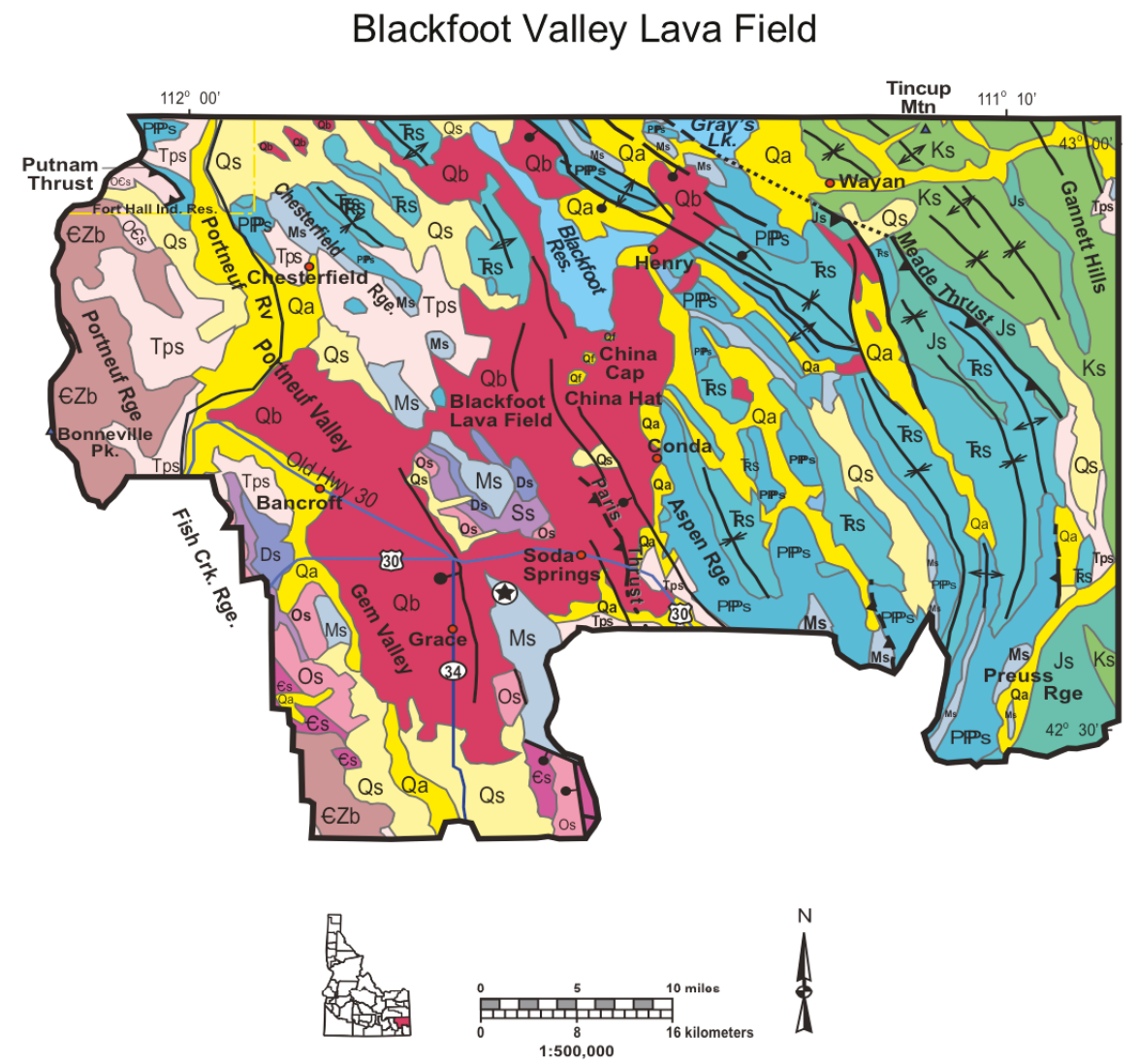

Figure 3. Location of study area and geology of the Blackfoot Lava Field (Soda Springs field site).

\section{Local Geologic Setting Blackfoot Valley Lava Field (Soda Springs)}

The local geology of the Soda Spring area consists of the Soda Springs Hills, which are on the west side of the study area and primarily are composed of early to middle Paleozoic marine quartzites, limestones, and dolomites. The Aspen Range located on the east side of the study area, consists mainly of late Paleozoic and Mesozoic marine limestones, dolomites, siltstones, and shales. Quaternary basalts and intercalated sediments associated with the Blackfoot Lava Field are located north of the study area fill valleys (Figure 4). In addition, several approximate 100,000 year old rhyolite domes (Armstrong et al. 1975) are situated within the BVF north of Soda Springs.

\section{Regional Hydrology}

The major hydrology features in the study area (near Soda Springs) are the presence of two aquifer systems. A deep highly $\mathrm{CO}_{2}$-charged aquifer that is presumably confined at depth by a series of thoelitic basalt flows and a shallow fresh water aquifer that is perched on top of the afore-mentioned basalts. In general, the basalt that host these aquifers are highly permeable; with permeability increasing to the north the farther one gets from the Soda Springs $\mathrm{CO}_{2}$ influence. In the area of Soda Springs, the $\mathrm{CO}_{2}$ influence has dramatically reduced permeability in the basalts due to secondary mineralization in conductive structure in the basalt. 


\section{Shallow Fresh Water Aquifer}

The protection of the aquifer system from anthropogenic generated metals contamination is the primary driver for this work. There is significant concern that contamination generated by the processing of phosphate at Monsanto and other facilities may be an ongoing issue. Critical to protecting the aquifer system is the identification of leakage pathways that could transmit contamination from the surface.

The Soda Springs area is located in an arid environment with a mean annual precipitation of $48 \mathrm{~cm}$. June has the highest mean monthly precipitation and July has the lowest mean precipitation. Mean annual snowfall is $330 \mathrm{~cm}$. Average annual pan evaporation exceeds 90 $\mathrm{cm}$, roughly two times the average annual precipitation, which likely results in little or no meteoric water infiltration in the valley and the nearby mountains. Groundwater flow in the Blackfoot Valley aquifer is generally from north to south, with the Bear River marking the southern boundary of the system (Figure 4). Most of the recharge to the system takes place in the form of leakage from the Blackfoot Reservoir and, to a lesser extent, from melting snow where Paleozoic formations outcrop in the northwest trending mountain ranges (Mayo et al. 1985).

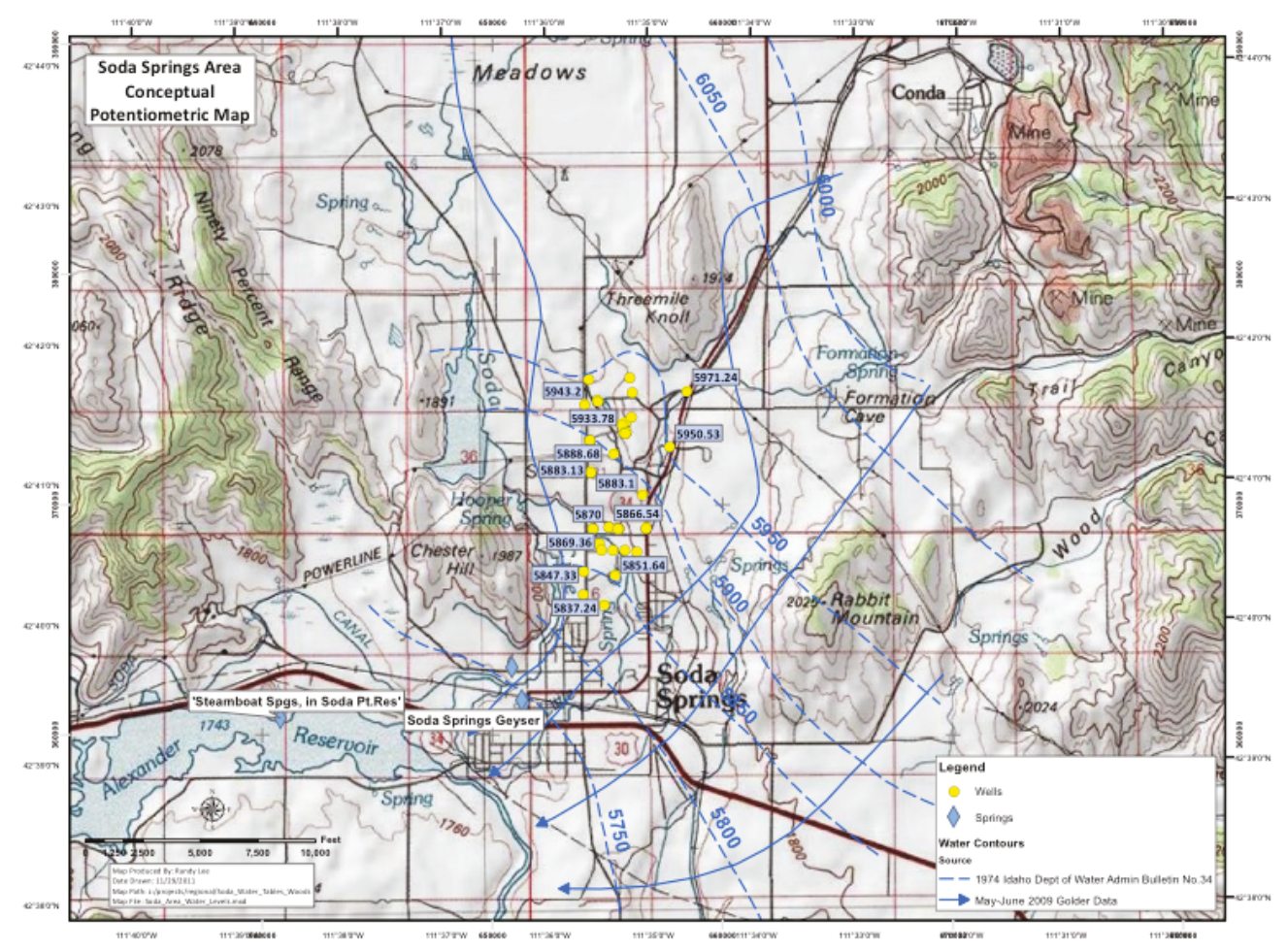

Figure 4 Potentiometric map of groundwater flow direction in the Blackfoot Valley Field aquifer

Historically, there is no mention of a freshwater aquifer system in the Blackfoot Valley. Irrigation and water supply are derived from Soda Creek and fresh water springs located on the far eastern side of the valley. However, construction of the Blackfoot Reservoir in 1910 created a major change in the hydrology of the system. The reservoir is constructed on fractured basalts, allowing for significant water leakage into the Blackfoot Valley stream 
(Soda Creek) and aquifer system, which flows south toward the Bear River (Dion 1974). Shortly after construction of the Dam in 1910, it was noticed that leakage from the reservoir had converted productive agriculture ground north of Soda Springs into "unproductive" marshland. At the same time, it was noticed that Soda Creek, which drains the Blackfoot valley, more than doubled in discharge in a matter of a few months (Manfield 1927). Subsequent hydraulic investigations have quantitatively supported the impact that leakage has had on the hydrology of the Blackfoot Valley (Dion 1974). In fact, a plan proposed in the 1970 s to raise the dam $2 \mathrm{~m}$ to increase storage was canceled because it was determined that the leakage caused by the increase in the dam height would increase aquifer and creek flow in the Blackfoot Valley by more than $60 \%$, leading to only a moderate increase in flow to irrigators farther to the west.

The aquifer in the area ranges from a highly productive system in the north to a fairly productive system in the southern portion of the valley. Yields range from 800 to more than $13,000 \mathrm{~L} /$ minute and specific capacities of 0.3 to $4,4000 \mathrm{~L} /$ minute per meter of draw down. Dion (1974), suggests that mineralization in the southern portion of the valley in the area of the City of Soda Springs has dramatically decreased aquifer productivity. And therefore restricts the vertical flow of gas and water to narrow highly fractured regions of the vadose zone. Stream discharge in Soda Creek (Figure 4), which is entirely effluent, is fairly stable on an annual basis, with stream discharge averaging $1.5 \mathrm{~m}^{3} /$ second.

\section{Scope}

Radon concentrations in soil, and the subsequent emanation rate of radon into soil gas, are affected by numerous factors including Ra-226 concentrations in the soil and rock matrix, soil moisture, fracture density in rock formations, barometric pressure, and the 3.8-day radioactive half-life of $\mathrm{Rn}-222$. All of these factors affect the transport of Rn-222 gas through the rock/soil matrix. Due to the complexity of Rn-222 emanation into soil gas, and the subsequent soil gas transport mechanisms, short duration measurements such as those made by devices such as RAD7 (http://www.durridge.com/products_rad7.shtm) are problematic at the scale of this project. In this context, the present study aims to provide a survey using inexpensive CR-39 particle track detectors to try and elucidate fracture networks that are actively transporting gas and water and by association contaminants into the subsurface. These detectors are deployed over a longer time frame (days to months). The CR-39 particle track detectors provide a method that is not hindered by short-term fluctuations in barometric pressure and soil moisture content. However, given that the flux of Rn-222 was unknown at the site, the original scope called for multiple deployments to try and bracket the exposure time needed for the detectors to effective. Due to contracting issues the project was only able to do two deployments, the first deployment was for 16 days. This exposure time was based on a successful survey completed at Fort Devens Massachusetts and was expected to be at the low exposure range at the Soda Springs site. The second survey was for 70 days and was based on the lack of signal observed during the 16-day survey. As it turns out and as it will be explained later, 16 days of exposure was too short and 70 days way slightly too long. If we had been able to do another deployment at 50-60 days our resolution of our results would have been much greater. 


\section{Project Deliverables:}

1. Assessing the cost and time required to deploy the technology at the Greenfield Environmental Multistate Trust LLC property located in Soda Springs

2. Quantifying the time required to construct the casings in the field

3. Determining what tools are required to install the casings in an alluvium covering the fractured rock (does installation require a power probe, a hand auger, a post-hole digger, etc.).

4. Evaluating the CR-39 exposure time required for achieving the necessary signal to noise ratio needed for a statistical analysis of the data

5. Determining the spatial resolution of the technique

6. What is the minimum size of the fracture or fracture network that can be resolved with this tool?

7. What is the detector spacing required to measure the features of interest?

\section{Progress}

INL has completed all seven tasks associated with this project. The degree of success experienced in this project was affected by the limited time to conduct the tests and the difficulty in drilling the holes for the gas ports. The difficulties were mostly associated with the contracting mechanism? that has to be used for this particular project. All parties worked extremely hard to get the contract in place; however, the end result was that the field team had only two months to conduct the work. This was roughly one-third of the time that the project was estimated to require. In spite of these difficulties, the project was remarkably successful in several areas, including 1) field deployment of gas portals, 2) reduction of cost associated with deployment 3) Determining what tools are needed for deployment in difficult environments and 4) Defining pre-deployment characterization needs. Because of the contracting delays the analysis of the field data and the delivery of the final report have been pushed into the second quarter of FY-15.

\section{Deliverable 1: Assessing the cost and time required to deploy the technology at the Greenfield Environmental Multistate Trust LLC property located in Soda Springs}

Because the field team had conducted a similar CR-39 detector study two years previously at Fort Devens the team had some reasonable estimates for cost and time required to do the work. However, because the previous study was a technical assistance project and EPA covered some of the deployment cost, there were large error bars on those estimates. We estimated at Fort Devens that materials cost for one gas port and one CR-39 detector (Accustar) was approximately $\$ 12.50$ for the detector and $\$ 5.00$ for the gas port materials. This did not include the labor or transportation required to assemble the gas ports (Figure 5). Costs for this study were carefully tracked and are reported in table 1. Multiple deployments in each gas port increase the total cost slightly, but the cost per measurement drops proportionally. In our study, the gas ports were each used for two measurements. 
These cost do not include labor or travel to the field as these costs are relative to the organization doing the work and the distance from their base of operations.

\begin{tabular}{|l|l|l|l|l|l|l|}
\hline Item & $\begin{array}{l}\text { CR-39 } \\
\text { detector } \\
\text { (includes } \\
\text { analysis) }\end{array}$ & $\begin{array}{l}\text { Composite } \\
\text { liner }\end{array}$ & $\begin{array}{l}\text { Gasport } \\
\text { caps }\end{array}$ & Misc & $\begin{array}{l}\text { Field cost } \\
\text { (auger, gas, } \\
\text { misc.) }\end{array}$ & Total cost per unit \\
\hline Cost & $\$ 12.60$ & $\$ 6.75$ & $\$ 8.00$ & $\$ .50$ & $\$ 4.00$ & $\$ 31.85$ \\
\hline
\end{tabular}

Table 1

By any measure, the cost per measurement using this technology is orders of magnitude cheaper than any other methodology. Even as was the case in this study, where multiple surveys would be needed, the cost is still far below $\$ 50.00$ per analysis.

The result from this study reveals the need for pre-characterization of the site to be studied prior to deployment. At Fort Devens there was a large amount of data available for the study site; this helped the team define the spacing of the measurements and the total number of sample locations. This helped reduce the cost significantly and ensured a positive result. At Soda Springs, very little was known about the system, especially when it came to the effect that a large $\mathrm{CO}_{2}$ flux would have on attenuating the radon signal. This turned out to be a significant issue. There is no doubt that pre-characterizing the site would significantly increase the cost for this type of study. However, site characterization would likely already be part of the Record of Decision (ROD) for any industrial-scale cleanup operation.

\section{Deliverable 2: Quantifying the time required to construct the casings in the field}

For the field test at Fort Devens the gas portals were constructed at INL and drop shipped to the field site. To get a better idea of the logistics and time required to rapidly deploy a CR-39 survey at a previously uncharacterized site, the Team planned to construct the gas portals on site. However, after careful consideration, it was decided that INL was close enough to the field site (two hours) to be considered onsite. Because we did not have to ship the gas portals by common carrier and could carry them to the field in our vehicle, we elected to construct them in the laboratory. The two-man team purchased the materials at the local Home Depot and Lowes, and cut and assembled 45 (40 were needed, we built five extra) gas portals in approximately six hours. Even if the field site was a significant distance from the field teams home location, and providing the materials could be locally purchased, we believe the time to construct on-site would not be greater than one day for a study of similar size. 


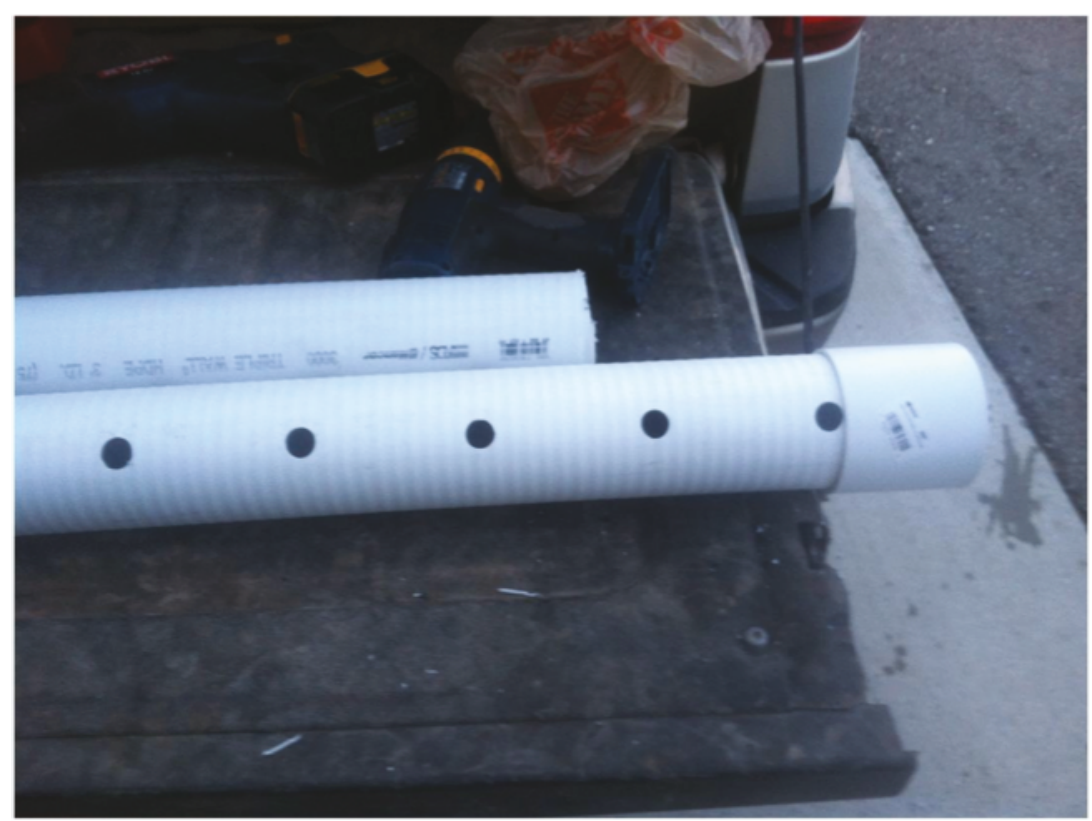

Figure 5 CR-39 Access portal developed by INL

\section{Deliverable 3: Determining what tools are required to install the casings in an alluvium covering the fractured rock (e.g. does installation require a power probe, a hand auger, a post-hole digger, etc.).}

Critical to being able to use the CR-39 detector approach to characterizing fields sites, is understanding what types of tool are needed to install the gas portals across a wide range of soil conditions. Ideally, the gas portals would be installed such that they were at the bedrock soil interface in order to minimize homogenization of the radon signal from a given fracture due to diffusion. In other words, the farther the detector is from a given fracture, the harder it will be to detect. At Fort Devens placing the portal at the bedrock soil interface was fairly easy, because there was only a thin layer of soil and leaf litter covering the glacially scoured granitic rock. However, at Soda Springs it was a bit more difficult, as the valley is filled with basalt flows covered by fluvial sediments of varying thickness. The sediments at Soda Springs are also problematic due to the occurrence of large irregularly spaced cobbles that make drilling holes difficult.

During the planning phase for the fieldwork, the team secured the use of a gasoline powered hydraulic six-inch auger from a local rental company. This is the same type of tool that was used during the Fort Devens study. At Soda Springs this auger system drilled holes fast and efficiently. However, there were some difficulties encountered. Most significantly, in almost half the holes drilled, we encountered a dense hardpan layer that we were not able to penetrate. The depth to this hard pan layer varied from a few inches to a few feet below ground surface. In some of the shallowest cases we were able to move the location of the gas portal a meter or two off axis and penetrate to sufficient depth. By being adaptable the team was able to place all 40 of the gas portals within 1-2 meters of the transect 
centerline. Based on our experience the team would recommend that future studies of this type at Soda Springs utilize larger more powerful auger system with a jackhammer to break up the hardpan. The second issue at Soda Springs was fact that the soil cover was much thicker (the hardpan zone by definition is considered part of the soil horizon) and could not be fully penetrated by the auger system that was used. Here again as mentioned above, including site characterization as part of the project should be included in any future study, regardless of where it takes place.

We recommend where possible, that powered equipment be used for placing the gas portals to minimize the strain on personnel. The more automated (the less physical exertion required by the field personnel) the more efficient and less time consuming the installation will be. And because labor is by far the largest cost associated with these kinds of studies, anything that will reduce man-hours will significantly reduce cost.

\section{Deliverable 4: Evaluating the CR-39 exposure time required for achieving the necessary signal to noise ratio needed for a statistical analysis of the data}

Due to long delays in getting funding to INL, the Project Team was not able to do a complete assessment for the correct exposure time at the Soda Springs Site. Additionally, the lack knowledge regarding the flux of Rn-222 made it more difficult to make an educated guess for exposure time. Due to the aforementioned contracting issues, the project was only able to do two deployments in each of the gas portals. The first deployment was for 16 days. This exposure time was based on a successful survey completed at Fort Devens and was expected to be at the low exposure range at Soda Springs. The rocks in the area do not contain as much natural radioactivity as does the granite of Fort Devens. When the CR-39 detectors for the first test were removed from the gas portals, they were replaced with a second set. The exposure time for the second deployment was to be determined based on the results of the first survey. When the first survey came back below detection limits, the team decided to run the second deployment for 70 days. The 70-day exposure time was decided upon in consultation with Accustar, the company that provided and analyzed the detectors and the lack of signal observed during the 16-day survey. The results of the second 70-day survey are presented in the figures for transects Hooper South (figure 7), Hooper Middle (figure 8), Hooper North (figure 9), and Sulphur Springs (figure 10). Overall the results of the 70-day survey were positive albeit the exposure time was slightly too long for some transects. The maximum exposure the CR-39 detectors can measure before being over saturated is 63 picocuries/liter. Many of our detectors came back as $>63 \mathrm{pCi} / \mathrm{l}$ and some right at that threshold. As was the case at Fort Devens, the number of oversaturated detectors is significant, but the data they provide is important, and can be used to evaluate the system. Over saturation of the detectors was a problem for two of the four transects, Hooper North and Sulphur Springs, where all but one of the detectors for each transect was oversaturated. 


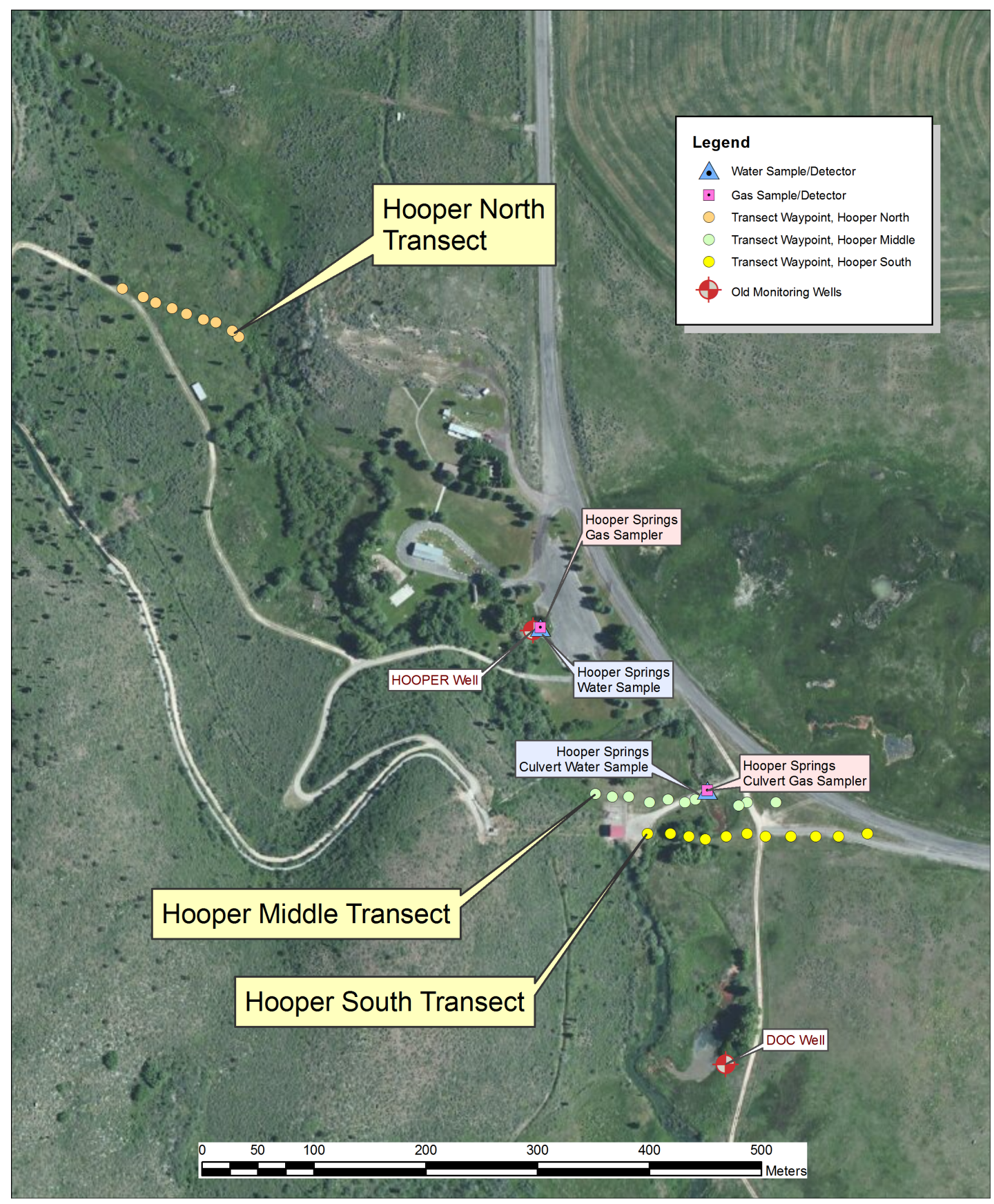

Figure 6 Hooper Transects 


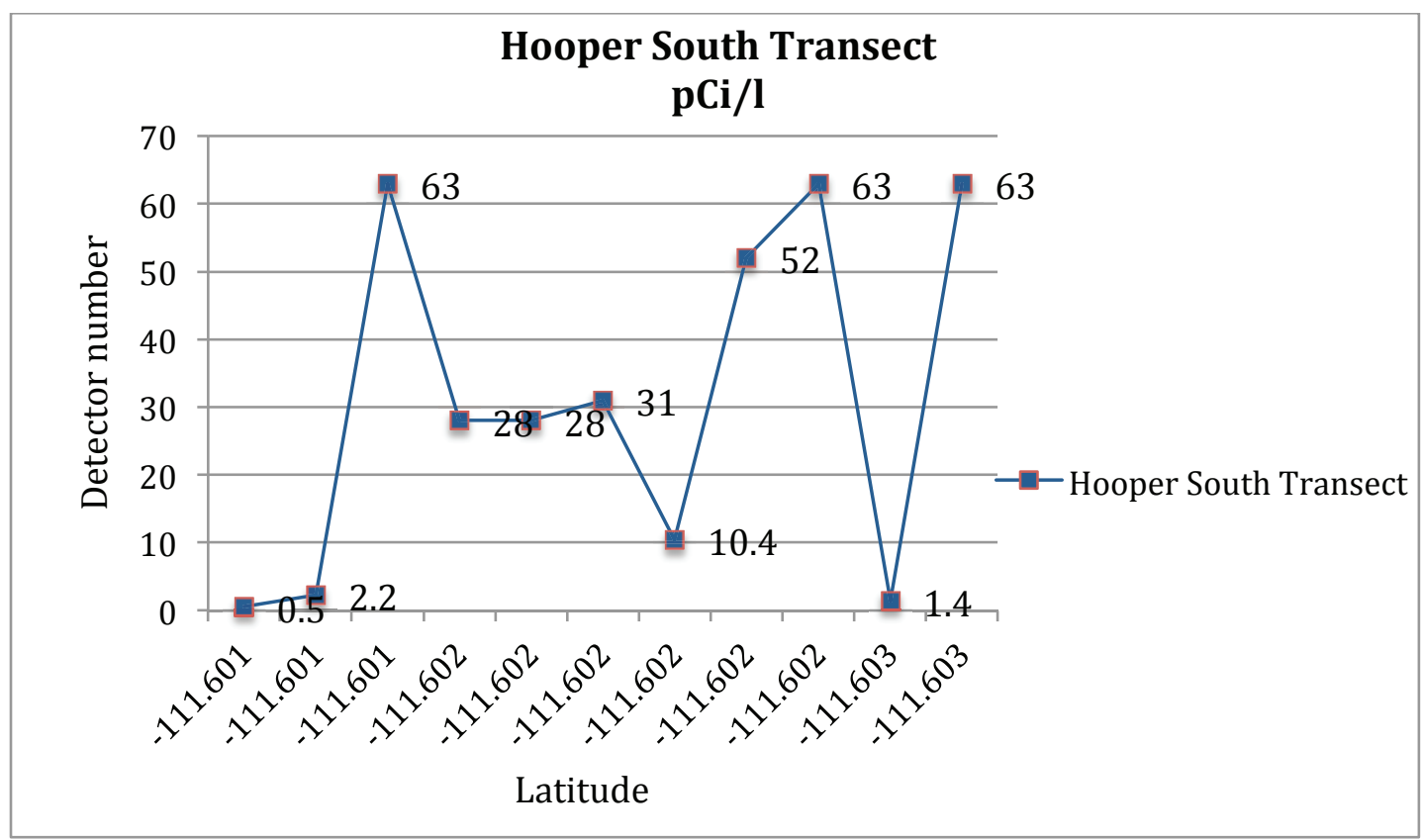

Figure 7 Radon exposure in pCi/L for the Hooper South Transect [is this 16 or 70 days?]

\section{Hooper South Transect}

The results for the Hooper South Transect (Figure 7) 70-day exposure are presented in figure 6. The data from this transect show by far the most character of the four surveyed. The data show three areas of interest, which represent differing degrees of radon influence or vertical communication with the gas portal. The values 0.5 to $2.2 \mathrm{pCi} / \mathrm{L}$ represent an area along the transect where vertical migration of gases (radon) between the surface and deep subsurface is non-existent or minuscule. These numbers represent areas where there are no significant open fractures and therefore are areas where one would not expect vertical leakage of water or gasses. The number 10.5 to $31 \mathrm{pCi} / \mathrm{l}$ indicates that the central part of this transect has a fracture network that is either very tight or does not have many factures. When compared the gas ports to the east where there is near zero radon exposure, in this area there would exist the possibility for some vertical water infiltration. The values of 52 to $63 \mathrm{pCi} / \mathrm{l}$ (63 being oversaturated) represent an area of the transect with the highest vertical communication. In this part of the transect there appear to be more intercommunicating fractures capable of vertically transporting water and gasses. This result is not unexpected, as the high values are located along the western reach of the transect near the area where a major range bounding fault is projected to be present in the subsurface. 


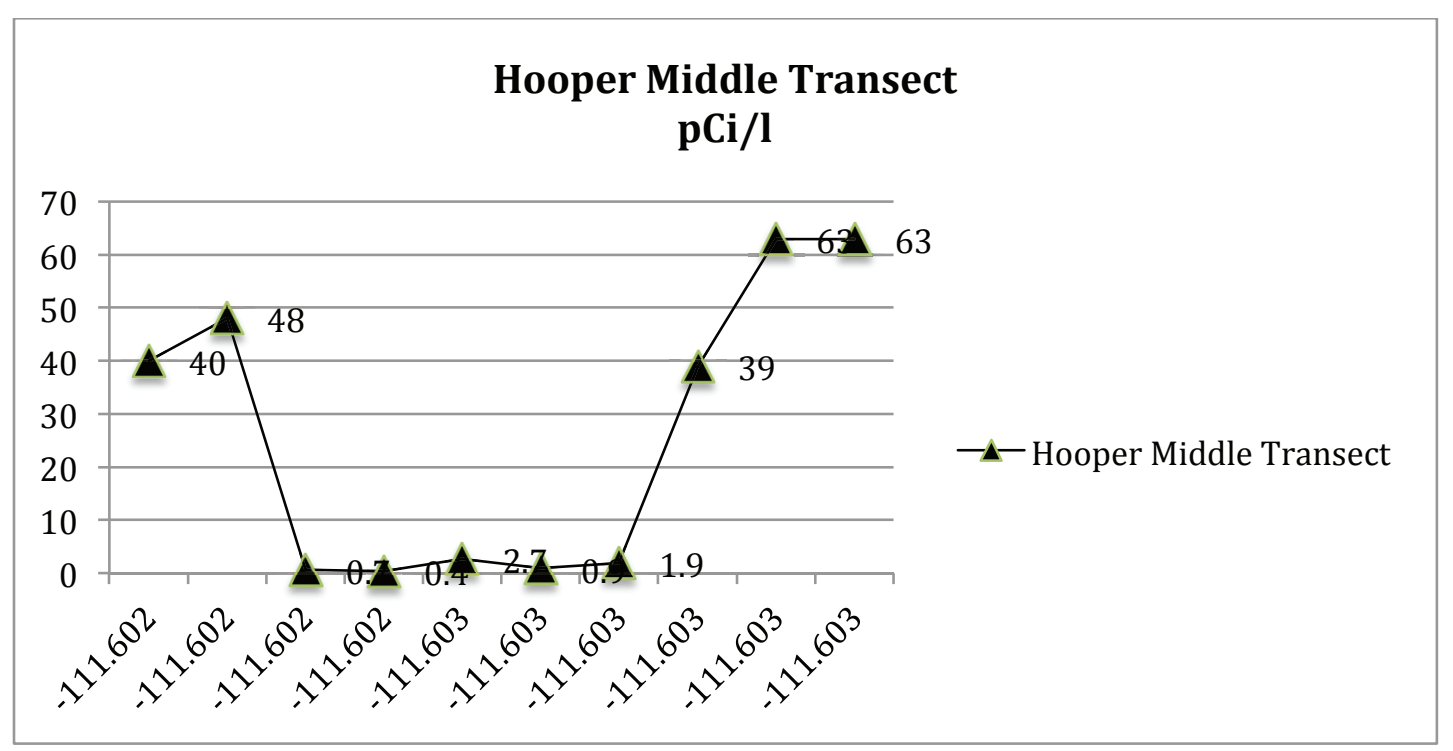

Figure 8 Radon exposure in pCi/L for the Hooper Middle Transect

\section{Hooper Middle Transect}

The results (figure 7) from the Hooper Middle Transect (point 15 figure 2), are very interesting, and although only about 20 meters north of the Hooper South Transect, it exhibits significantly different character. Along the whole central portion this transect, the extremely low levels of radon detected suggest very tight (unfractured) conditions, indicating very little or no vertical gas communication (and therefore little potential for water infiltration). The eastern and western boundaries of this transect indicate a much more open system, especially along the western edge. Like the Hooper South Transect, the gas ports with the highest detected radon values are nearest the suspected location of the range bounding fault. The results from this transect are the most consistent with the conceptual model for the site. While we have a potential explanation for the high values in the western section of the transect, the relatively high values on the east is a bit more problematic. Clearly there are intercommunicating fracture(s) under this area, but it is not possible to say anything more conclusive. 


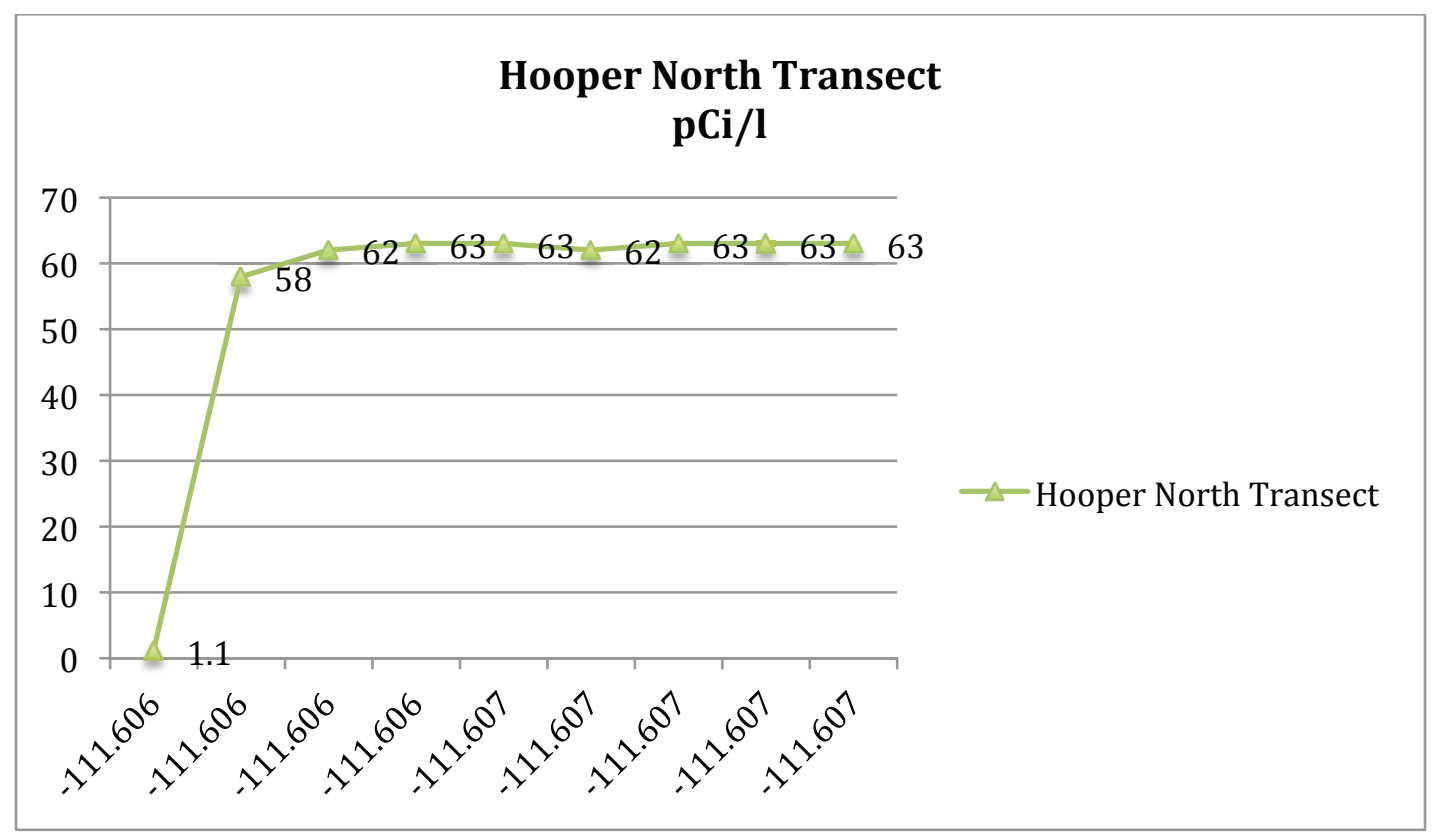

Figure 9 Radon exposure in pCi/L for the Hooper North Transect

\section{Hooper North Transect}

This transect is an anomaly for the Hooper Springs study site, all but one of the CR-39 detectors were over saturated ( $>63 \mathrm{piC} / \mathrm{l}$ ) Figure 8$)$. Unlike the south and middle transects, this transect did have a notable soil cover with abundant plants and grasses. During the 70 day survey the flux was sufficient to saturate the CR-39 detectors, however, during 16-day survey all of the detectors in this transect came back with non-detectable exposure. The difficulty in interpreting these results is that 16 days was too little time and 70 days was too much time to elucidate any character or small-scale variation along the transect. It is also worth noting, that the thick soil abundant plant cover coupled with the fact that the gas port did not reach the soil bedrock interface may have created a diffusion dominated system, which may produce the effect of averaging the radon signal over the affected portion of the study area. The one outlier is the point located nearest Soda Creek, which measured 1.1 $\mathrm{piC} / \mathrm{l}$, and may reflect the effects of an impermeable zone associated with sediment deposited by the fluvial system. Whatever the case, an intermediate-length exposure survey would most certainly have been more informative.

\section{Sulphur Springs Transect}

The Sulphur Springs transect (point 18 figure 2) is located approximately $8.4 \mathrm{~km}$ south west of the Hooper transects in an area of very high $\mathrm{CO}_{2}$ flux. Where Hooper transects were approximately 150 meters long, the Sulphur transect is an order of magnitude longer at $1.5 \mathrm{~km}$. It was hypothesized that by placing the detectors further apart, the study could shed some light on the scale at which the methodology could resolve leaking fractures. Unfortunately, as was the case with the Hooper north survey, all but one of the detectors was over saturated (figure 9). Of the four surveys locations, the team encountered the most difficulty with this location. Although the area immediately proximal to 
the survey is agriculture land that is routinely plowed, our survey location along the main road was extremely difficult to drill, due to road base materials, and or a persistent hardpan zone.

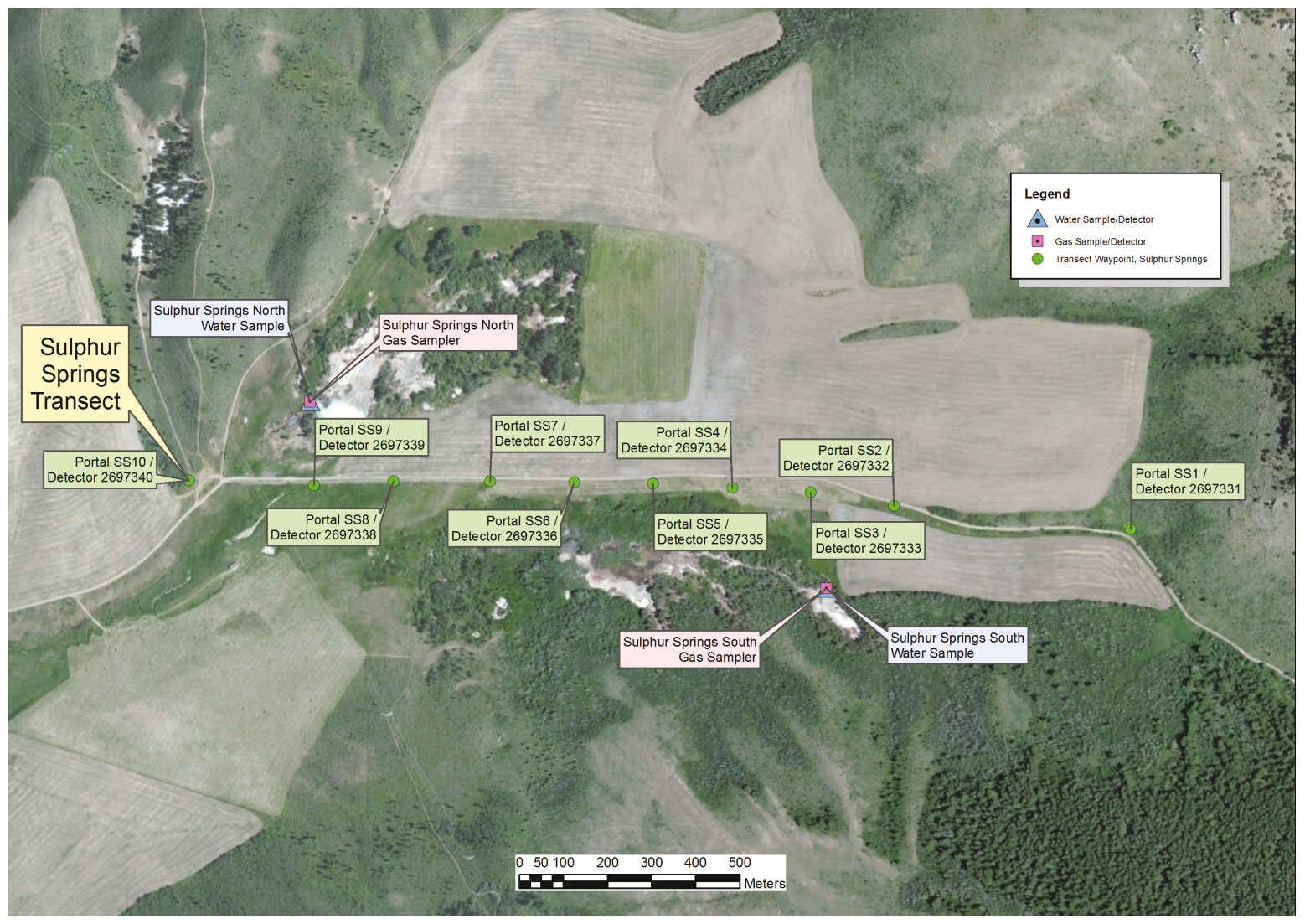

Figure 10 East West cross-section at the Sulphur Springs study location

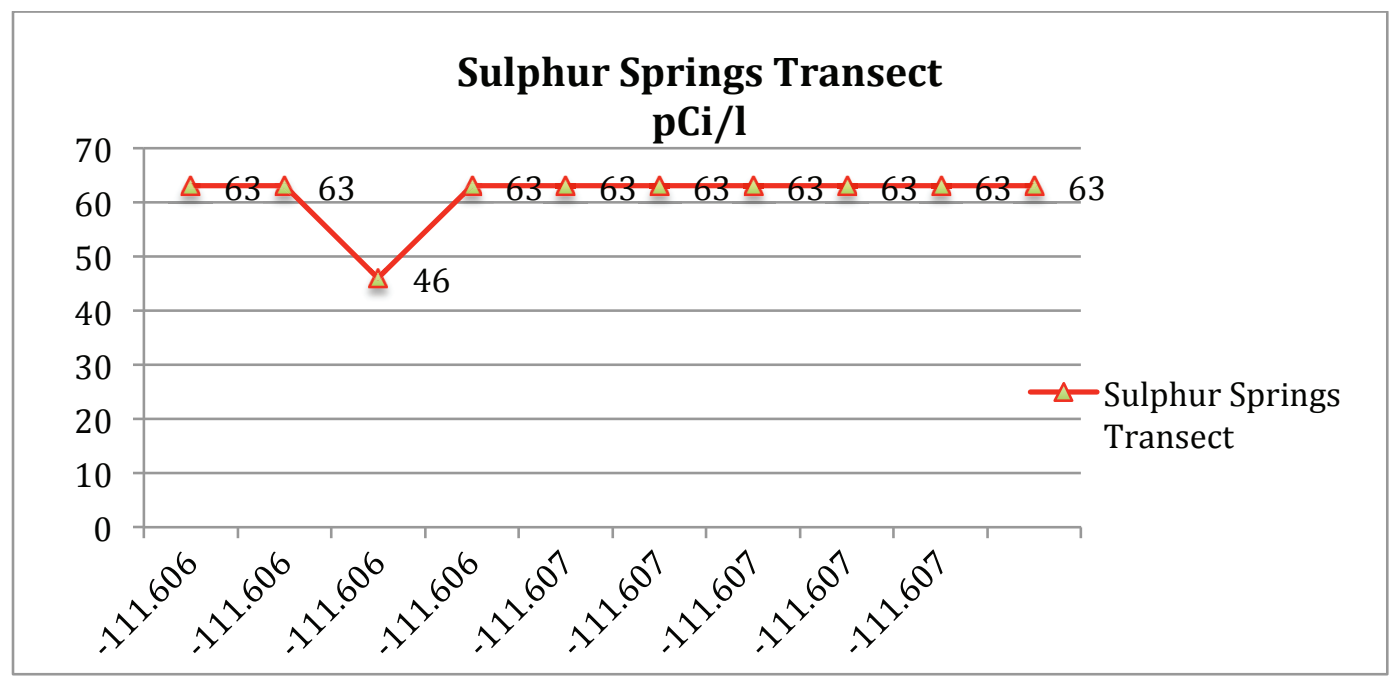

Figure 11 Radon exposure in pCi/L for the Sulphur Springs Transect 
This difficulty required that the field team move many of the gas ports to locations where the auger could drill to a sufficient depth. Additionally, this location a fault bounded valley with a thick alluvial layer covering the bedrock, which occurs at an unknown depth. The location of an eastwest transect was based on the existence of two high $\mathrm{CO}_{2}$ springs (Figure 10) that exist along a northeast southwest trend. By placing the transect such that it crossed these two features (figure 10), the team hypothesized the transect would encounter the buried fracture system responsible for these two prolific gas emitting springs. The hypothesis seemed to be reasonable as it was assumed that the $\mathrm{CO}_{2}$ features were interconnected by a shared common fracture system in the subsurface (which acts as a subsurface "plumbing" system); the area in between simply having been buried by geologic processes and human activities (i.e. farming and road building). In the end, due to the over- exposure of the detectors during the 70-day survey, and the lack of signal during the 16-day survey, little insight was provided into the geologic characteristics of the fracture system. In fact, the only detector that was not oversaturated ( $46 \mathrm{pCi} / \mathrm{l}$ ) is port SS8 (figure 9), is located exactly where we would have expected to have the highest flux. While it is possible that this detector was not over saturated due to a very high $\mathrm{CO}_{2}$ flux that diluted and radon signature, it is impossible to say anything more conclusive.

\section{Summary}

Given the limited time, extreme weather, and shortage of resources, the conclusions from this study are mostly positive. The weather's impact on the results of this study cannot be addressed directly, but most certainly had an impact. Starting on the first day of fieldwork and ending almost simultaneously with the conclusion of the surveys, eastern Idaho experienced a period of extremely high rainfall. This extended period of precipitation was the second highest in recorded history. This period of precipitation destroyed crops, caused landslides and washed out roads all over eastern Idaho, but was especially severe in the study area. While the full impact to our study is impossible to quantify, it most certainly affected the lack of signal we observed in the 16-day study. At the study site, the 16-day period from July 16 through August 1, experienced daily torrential rain. It is highly likely that this rainfall caused a pulse of infiltrating water that suppressed the radon flux to the surface. In turn, the lack of signal in the 16-day survey caused the team to extend the second survey from 30 days to 70 days to try and capture a detectable radon flux. As it turns out, 70 days was slightly too long at Hooper Springs and was probably significantly too long at Sulphur Springs. In the absence of another study, all of this is conjecture based on post survey analysis.

We did learn that surveys such as this conducted with very little background data could be successful to a certain degree. However, the ability to do some pre-characterization, including drilling holes and conducting some background gas measurements would have dramatically improved the dataset. That being said, the amount of heterogeneity that the study captured is remarkable given the constraints. For example at Hooper Springs we discovered that the resolution of the methodology could see fracture flow on a scale of meters. The difference in signal between the Hooper South transect and the Hooper North transect located along parallel strike 20 meters apart was dramatic (figures 6 and 7). This implies that with proper siting and detector spacing, it is possible to evaluate the fracture 
flow paths for contaminants migrating from the surface to an aquifer receptor at a cleanup site. Most importantly, with some modification of the methodology based on the lessons from Fort Devens and Soda Springs, these types of studies could provide invaluable data for scientists and engineers at a cost that is orders of magnitude less than currently-available technology. 